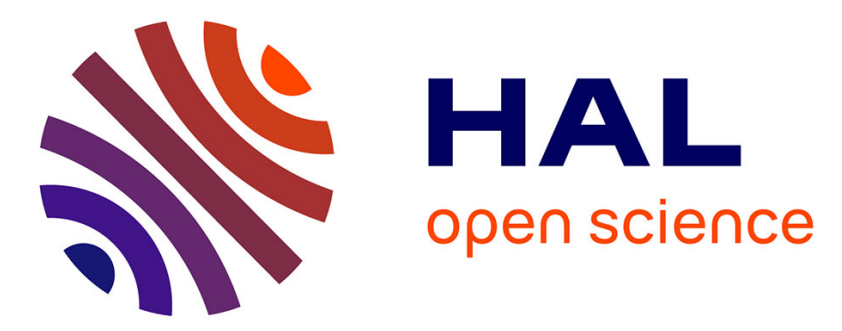

\title{
Vladimir's Choice and the Distribution of Social Resources
}

\author{
Jim Sidanius, Hillary Haley, Ludwin Molina, Felicia Pratto
}

\section{To cite this version:}

Jim Sidanius, Hillary Haley, Ludwin Molina, Felicia Pratto. Vladimir's Choice and the Distribution of Social Resources. Group Processes and Intergroup Relations, 2007, 10 (2), pp.257-265. 10.1177/1368430207074732 . hal-00571648

\section{HAL Id: hal-00571648 https://hal.science/hal-00571648}

Submitted on 1 Mar 2011

HAL is a multi-disciplinary open access archive for the deposit and dissemination of scientific research documents, whether they are published or not. The documents may come from teaching and research institutions in France or abroad, or from public or private research centers.
L'archive ouverte pluridisciplinaire HAL, est destinée au dépôt et à la diffusion de documents scientifiques de niveau recherche, publiés ou non, émanant des établissements d'enseignement et de recherche français ou étrangers, des laboratoires publics ou privés. 


\title{
Vladimir's Choice and the Distribution of Social Resources: A Group Dominance Perspective
}

\author{
Jim Sidanius \\ Harvard University \\ Hillary Haley and Ludwin Molina \\ UCLA \\ Felicia Pratto \\ University of Connecticut
}

\begin{abstract}
'Vladimir's choice' refers to the tendency for people to favor the ingroup relative to the outgroup-even when doing so requires that people sacrifice ingroup profits in absolute terms. We investigated correlates of this tendency by asking a sample of White undergraduates to complete an allocation task using a resource allocation matrix. While there was a slight tendency for Vladimir's choice to increase with increasing levels of ethnic identification, this tendency disappeared when other factors were considered. Consistent with realistic group conflict theory and social dominance theory, the tendency to make Vladimir's choice increased with increasing levels of perceived intergroup competition and social dominance orientation.
\end{abstract}

KEYWORDS group conflict, social allocation, social dominance orientation, social identity

One day God came down to Vladimir, a poor peasant, and said: 'Vladimir, I will grant you one wish. Anything you want will be yours'. However, God added: 'There is one condition. Anything I give to you will be granted to your neighbor, Ivan, twice over'. Vladimir immediately answered, saying: 'OK, take out one of my eyes.' Eastern European fable

THis fable illustrates one of the most disturbing and fascinating human tendencies documented by research on social identity theory (SIT): the tendency for people to choose to disadvantage others, even when doing so comes at the cost of disadvantaging themselves. Early SIT research using the minimal groups paradigm (e.g. Tajfel, Billig, Bundy, \& Flament, 1971) showed that many people, when placed in an intergroup context, behave just as Vladimir does toward his neighbor. Specifically, when given allocation tasks, people tend to favor ingroup members over outgroup members-something that holds true even when group membership is determined on trivial or random bases. And such discrimination takes a special, 'group-comparative' form. In the

\section{$\overline{\text { Author's note }}$}

Address correspondence to Jim Sidanius, Department of Psychology, William James Hall, Harvard University, 33 Kirkland Street, Cambridge, MA, 02138, USA

[email: sidanius@WJH.Harvard.edu] 
language of early social identity researchers, people tend to follow a strategy of maximum difference (MD) rather than maximum in-group profit (MIP) or maximum joint profit (MJP; Tajfel \& Turner, 1986, p. 14) in more colloquial terms, it appears that people are more interested in showing up their outgroups than in profiting their ingroup per se.

Much research has sought to account for this pattern of findings, and various hypotheses have been ruled out. For example, this basic tendency for discrimination cannot be explained simply in terms of participants' self-interest or group-interest (Billig \& Tajfel, 1973; Gagnon \& Bourhis, 1996; Perreault \& Bourhis, 1998). It cannot be explained in terms of demand characteristics (Turner, 1975). And, despite the elegance of 'rational actor' and 'homo economicus' arguments (Becker, 1957), which suggest that people are motivated to achieve maximal ingroup gains regardless of outgroup outcomes, these arguments apparently do a poor job of explaining social identity phenomena. Indeed, a steady and consistent line of research shows that some people make 'Vladimir's choice' (i.e. follow an MD strategy) even when doing so clearly minimizes absolute ingroup gains (e.g. Hogg \& Abrams, 1990; Tajfel \& Turner, 1986; Turner, 1975; Turner, Hogg, Oakes, Reicher, \& Wetherell, 1987).

SIT offers a cogent accounting of this pattern of findings. According to SIT, people base their identities, in part, on the social groups to which they belong. Thus people possess, in addition to unique personal identities, social identities-identities that reflect their group memberships (see Tajfel, 1978, p. 63). According to SIT, people also have a critical need to see themselves in a positive light, or to maintain (or achieve) a positive self-concept. It is therefore believed that people strive to maintain (or acquire) positive social identities, which-SIT suggests-are based largely on favorable ingroup-outgroup comparisons (i.e. assessments of ingroups relative to outgroups; see Turner, 1975).

SIT maintains that people show ingroup preferences in minimal group studies because the existence of minimal group categorizations (in the absence of 'real' competing group interests) is sufficient to invoke people's fundamental interest in laying claim to a positive social identity. That said, SIT also holds that 'real' groups, particularly those to which people feel most tied, are likely to exert the greatest control over behavior. That is, everything else being equal, the more strongly people identify with the ingroup (i.e. the more potent that social identification), the more likely they should be to make Vladimir's choice (i.e. use an MD strategy; see Hogg \& Abrams, 1990).

SIT also maintains that socio-structural parameters such as group status, status stability, status legitimacy, and permeability of group boundaries affect people's tendency to discriminate (Bettencourt, Charlton, Dorr, \& Hume, 2001; Tajfel \& Turner, 1986). In particular, and also consistent with the expectations of realistic group conflict theory (Bobo, 1988), because SIT posits that positive social identity is based largely on assessments of ingroups relative to outgroups, it follows that the more competition people perceive between groups (i.e. the more relevant outgroups are for assessing ingroup success), the more likely people should be to make Vladimir's choice when completing an allocation task. In short, social identity theorists suggest that group-based discrimination largely serves to enable people to maintain (or achieve) positive self-regard (Tajfel \& Turner, 1986); that it entails positive assessments of ingroups relative to outgroups; and that it can be enhanced by ingroup identification. The reasoning of SIT further suggests that group-based discrimination should be enhanced by perceptions of intergroup competition.

Social dominance theorists concur with the SIT interpretation of people's tendency to make Vladimir's choice. They agree, for example, that discrimination can be elicited on the basis of trivial ingroup/outgroup classifications, that it is often 'group-comparative' in nature, and that it is likely to be enhanced by both ingroup identification and perceptions of group competition. But social dominance theorists also make an additional prediction. Namely, the tendency to make Vladimir's choice should also be related to social dominance orientation (SDO) among members of relatively high-status groups (see 
Pratto, Sidanius, Stallworth \& Malle, 1994). While this prediction has never been explicitly tested, it follows directly from the logic of social dominance theory: the greater one's desire to maintain and establish group-based social hierarchy, the more likely one should be to endorse the relative advantage of dominant groups over subordinate groups, even if that advantage comes at the cost of reduced absolute gains for the dominant group (see Sidanius \& Pratto, 1999).

Thus, the purpose of this research is quite straightforward. We are interested in determining the degree to which both perceived zero-sum intergroup competition and SDO contribute to Vladimir's choice allocation decisions, over and above the effects of social identification that have been so broadly demonstrated by social identity research.

\section{Method}

\section{Participants}

The sample consisted of 186 White undergraduates from the University of California, Los Angeles (UCLA), all of whom were US citizens. Participants were recruited for participation by the offer of four (randomly distributed) US $\$ 50$ prizes. There were 89 males, 96 females, and 1 student who did not indicate a gender.

\section{Procedure}

Participants in this study were asked to complete a 13-page questionnaire, which included measures of ethnic identification, perceived group competition, SDO, economic conservatism, and gender. At the end of this questionnaire, all participants were given an identical allocation task (see Appendix 1).

In the allocation task they were told that the Regents of the University of California had decided to allocate an unspecified amount of money to predominantly White and minority student organizations, and they were asked to select-among seven different options-the breakdown of funds that they felt should be made. The setup of these seven options was inspired by, but not identical to, the basic allocation structure used by Tajfel (1978). At one extreme, participants could opt to give relatively large amounts of money to both predominantly White and minority organizations, but predominantly White organizations would receive slightly less money than minority organizations (19 million vs. 25 million). At the other extreme, participants could opt to give both groups relatively small amounts of money, but in this case predominantly White organizations would receive more money than minority organizations ( 7 million vs. 1 million). Thus, in line with the primary focus of this article, absolute gains (i.e. maximizing the amount of money given to the ingroup and maximum joint return) were pitted against relative gains (i.e. maximizing the ratio between ingroup gains and outgroup gains). It should be recognized that social identity theorists have, historically, made use of a variety of different allocation matrices and measurement techniques for assessing preferences (see Bourhis \& Gagnon, 2001; Bourhis, Sachdev, \& Gagnon, 1994 for reviews). Because the tendency to prefer relative to absolute gains was the sole dependent variable of interest in this research, however, no other matrices were presented to participants. $^{1}$

\section{Variables}

Ethnic group identification On the first page of the questionnaire, respondents were asked to classify themselves into one of several different ethnic groups, following the question: 'Which ethnic group do you belong to?' The choices included groups such as 'African American', 'White', 'Latino/Chicano', 'Asian American', and 'Other (please specify)'. Only students selecting 'White' were included in the present analysis.

After respondents were primed with these ethnic categories, they were asked four questions about identification with their ethnic group (1 - not at all, 7 - very): (1) 'How strongly do you identify with other members of your ethnic group?', (2) 'How important is your ethnicity to your identity?', (3) 'How often do you think of yourself as a member of your ethnic group?', and (4) 'How close do you feel to other members of your ethnic group?' These items formed a reliable ethnic identification scale $(\alpha=.82)$. 
Perceived group competition Two questions placed toward the middle of the questionnaire (on page 6) measured the degree to which students perceived zero-sum competition between Whites and minorities: (1) 'Better jobs for African Americans means fewer good jobs for Whites', (2) 'The economic advancement of certain groups threatens the advancement of other ethnic groups'. (1 - strongly disagree, 7 - strongly agree). These items formed a perceived group competition scale with adequate reliability $(\alpha=.68)$.

SDO SDO was also measured toward the middle of the questionnaire (on page 5). This construct was measured using the comprehensive 16 -item $\mathrm{SDO}_{6}$ Scale. As is standard practice, the measure used a 1-7 scale, where high scores indicated high degrees of SDO $(\alpha=.91)$. The $\mathrm{SDO}_{6}$ Scale consists of items such as: 'Superior groups should dominate inferior groups'; 'Group equality should be our ideal' (reverse coded); and 'To get ahead in life, it is sometimes necessary to step on other groups' (see Pratto et al., 1994, for details).

Economic conservatism This single-item variable, measured toward the beginning of the questionnaire (on page 2), was included here so that we could control for economic conservatism when examining the effects of the other variables on Vladimir's choice. Respondents were asked: 'In terms of economic issues, how would you describe your political attitudes and beliefs?' Answers to this question were given on a 7-point scale, ranging from ' 1 - very liberal' to ' 7 - very conservative'.

Gender The very first item on the questionnaire (appearing on page 1) asked participants to indicate their gender. Males were coded as ' 1 ' and females as ' 2 '. Like economic conservatism, this variable was included as a control variable.

Vladimir's choice (VC) The dependent variable (the tendency to employ maximum differentiation instead of maximum ingroup profit or maximum joint profit, which we will term simply 'Vladimir's choice', or 'VC') was measured toward the end of the questionnaire, when participants were asked to make the allocation decision concerning White and minority student organizations. ${ }^{2}$ This variable was measured on a 7-point scale. A score of ' 1 ' indicated a strong tendency to prefer absolute profits to relative profits (the decision to give $\$ 19$ million to White groups and $\$ 25$ million to minority groups). A score of ' 1 ' would thus be consistent with a MIP or MJP allocation rule. A (midpoint) score of '4', on the other hand, reflected a simple 'parity allocation' (the decision to give $\$ 13$ million to each group). And a score of ' 7 ' indicated a strong tendency to prefer relative profits to absolute profits (the decision to give $\$ 7$ million to White groups and $\$ 1$ million to minority groups). A score of ' 7 ' would therefore represent an MD, or extreme VC allocation rule.

\section{Results}

\section{Distribution of allocation decisions}

As can be seen in Table 1, only $11.4 \%$ of the students chose to allocate funds so as to maximize absolute profits (i.e. allocated $\$ 19$ million to Whites and $\$ 25$ million to minorities). Most of the students $(55.7 \%)$ instead chose to allocate smaller but equal amounts of money to both groups (i.e. $\$ 13$ million to each group). However, a minority of students $(4.5 \%)$ made the most extreme VC (i.e. extreme MD choice)

Table 1. Distribution of allocation decisions

\begin{tabular}{llllllll}
\hline \multicolumn{7}{c}{ Allocations to White versus minority student organizations (in millions of dollars) } \\
\hline 19 to Whites & 17 to Whites & 15 to Whites & 13 to Whites & 11 to Whites & 9 to Whites & 7 to Whites \\
vs. 25 to & vs. 21 to & vs. 17 to & vs. 13 to & vs. 9 to & vs. 5 to & vs. 1 to \\
minorities & minorities & minorities & minorities & minorities & minorities & Total \\
minorities & allocation \\
\hline $11.4 \%$ & $6.8 \%$ & $10.2 \%$ & $55.7 \%$ & $6.8 \%$ & $4.5 \%$ & $4.5 \%$ & $100.0 \%$ \\
$n=20$ & $n=12$ & $n=18$ & $n=98$ & $n=12$ & $n=8$ & $n=8$ & $N=176$ \\
\hline
\end{tabular}


by allocating $\$ 7$ million to Whites and only $\$ 1$ million to minorities. It is notable that both of these latter allocation strategies clearly deviate from the 'rational actor' paradigm, which presumes that people will opt to maximize ingroup profit, regardless of profits enjoyed by outgroups.

\section{Correlates of allocation decision}

The major focus of this inquiry is to explore whether or not ethnic identification, perceived group competition, and SDO, net of economic conservatism and gender, are related to these different social allocations. The product-moment correlation coefficients in Table 2 show that VC was related to four of the five independent variables. Specifically, VC was positively related to (a) increasing levels of economic conservatism $(r=.16, p<.05)$, (b) being male rather than female $(r=-.17, p<.01)$, (c) increasing levels of perceived group competition $(r=.23, p<.01)$, and (d) increasing levels of SDO $(r=.31, p<.001)$. The only variable that VC was not related to was ethnic identification $(r=.11, n s)$.

\section{Net covariates of $V C$}

We employed a multiple regression analysis to examine the net and total relationships of all five independent variables with VC. We also explored whether or not there were any two-way or three-way interactions between ethnic group identification, perceived group competition, and SDO. Specifically, we performed a fourstep hierarchical regression analysis with VC as the criterion variable, and the five variables discussed above as predictors. Employing Aiken \& West's (1991) multiple regression approach, mean-centered gender and economic conservatism were entered at Step 1; meancentered ethnic identification, perceived group competition, and SDO at Step 2; all two-way interactions among ethnic identification, perceived group competition, and SDO at Step 3; and the three-way interaction among these same variables at Step 4.

Table 3 reveals that at Step 1, gender and economic conservatism each made marginally significant and unique contributions to the

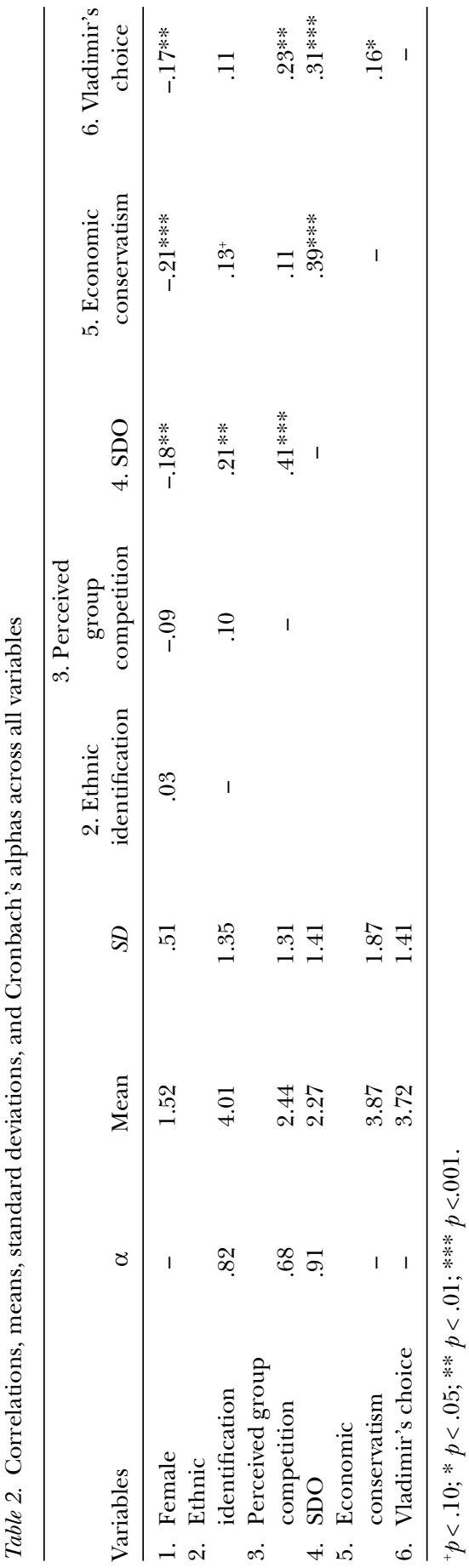


Table 3. Tendency to make Vladimir's choice as a function of ethnic identity, perceived group competition and SDO. (Entries are standardized multiple regressions coefficients)

\begin{tabular}{|c|c|c|c|c|}
\hline Independent variables & Stage 1 & Stage 2 & Stage 3 & Stage 4 \\
\hline Female & $-.15^{+}$ & -.12 & $-.12^{+}$ & $-.12^{+}$ \\
\hline Economic conservatism & $.13^{+}$ & .03 & .02 & .02 \\
\hline Perceived group competition & & $.18^{*}$ & $.17 *$ & $.17 *$ \\
\hline SDO & & $.27 * *$ & $.27 * *$ & $.27 * *$ \\
\hline Ethnic identification & & -.01 & -.01 & -.01 \\
\hline Ethnic identification $\times$ perceived group competition & & & .01 & .01 \\
\hline SDO $\times$ ethnic identification & & & -.05 & -.05 \\
\hline SDO $\times$ perceived group competition & & & .04 & .04 \\
\hline SDO $\times$ perceived group competition $\times$ ethnic identification & & & & .00 \\
\hline Significant increase in $R^{2}$ & $.05^{*}$ & $.12 * * *$ & .00 & .00 \\
\hline Adj. $R^{2}$ & $.04 *$ & $.14 * * *$ & $.13 * * *$ & $.13 * * *$ \\
\hline
\end{tabular}

${ }^{+} p<.10 ; * p<.05$ (one-tailed test); $* * p<.01$ (one-tailed test); $* * * p<.001$ (one-tailed test).

prediction of VC. However, the greatest contribution to the prediction of VC occurred at Step 2, when the effects of perceived group competition, SDO, and ethnic identification were added. Of these three variables, only SDO and perceived group competition made statistically significant and unique contributions: the higher one's level of SDO and the more one perceived intergroup competition, the greater one's likelihood of making VC $(\beta=.27, p<.01$; and $\beta=.18, p<.05$, respectively). The two- and three-way interaction (Steps 3 and 4) did not significantly predict VC.

\section{Summary and discussion}

Consistent with SIT, and at odds with the 'rational actor' perspective, our data suggest that people do not always seek to maximize absolute ingroup profit. In our simple allocation situation, this was illustrated by the fact that less than $12 \%$ of respondents maximized absolute returns to the ingroup. Rather, most respondents chose to allocate smaller, yet exactly equal, amounts of money to both the ingroup and outgroup. Thus it appears that for most participants, 'fairness', 'equity', or 'equality' motives trumped motives for absolute profit or relative advantage. At the same time, and as anticipated, a substantial percentage of participants $(15.8 \%)$ were apparently willing to sacrifice millions of dollars to ingroup organizations so long as these organizations received more money than outgroup organizations.

The major purpose of this article has been to determine if, net of social identification, the degree to which people are willing to sacrifice absolute gains for relative gains (i.e. make $\mathrm{VC}$ ) is related to perceived zero-sum competition between groups and to the desire for hierarchical relationships among groups (i.e. SDO). The data appear to be affirmative in both cases. Thus, these findings are consistent with the expectations of both realistic group conflict theory (see Bobo, 1988) and social dominance theory (Sidanius \& Pratto, 1999). It should be observed that, because our analysis controlled for economic conservatism, these effects cannot be attributed to purely ideological values regarding the economic distribution of resources in general.

Surprisingly, however, these results are also noteworthy in terms of what was not found. Most importantly, while there was a slight positive correlation between ingroup identification and VC, this correlation was not significant, especially when considered alongside the correlations for perceived group competition and SDO. The question naturally arises as to why ingroup identification did not play a larger role. In thinking about this problem, it is worth bearing in mind that the relationship between 
ingroup identification and ingroup bias has been found to be somewhat labile across studies (e.g. Hinkle \& Brown, 1990). In addressing this lability, Turner (1999) has argued that a substantial relationship between ingroup identification and ingroup bias is likely to emerge only under five conditions: (1) the individual categorizes herself in terms of membership in the relevant group; (2) the relevant social identity is salient with respect to the comparative judgment at hand; (3) the ingroup and outgroup are perceived to be interrelated within an overall social structure; (4) the dimension of intergroup comparison is relevant to intergroup status relationships; and (5) the outgroup is relevant to the particular comparative judgment being made.

Given Turner's conditions, should we have expected ingroup identification to be a strong predictor of VC in this study? Considering the long, infected history of race relations in the United States, and the highly charged and competitive relationships among ethnic groups on modern American campuses (e.g. see Crisostomo, 2001), we have strong reason to believe that all of Turner's conditions were satisfied. Furthermore, while it is generally recognized that ethnic group identification is not as salient or powerful for Whites as it is for ethnic minorities (e.g. Jaret \& Reitzes, 1999; Larkey \& Hecht, 1995), it should be borne in mind that SIT was initially developed to address racial discrimination (among Whites), and that in this study Whites' mean ethnic identification was moderately strong (i.e. 4.01 on a 1-7 scale) and clearly salient enough to covary with other relevant variables (e.g. SDO and economic conservatism).

That being said, it is also worth observing that the dependent variable used in this research is not a traditional SIT variable. Furthermore, it is worth considering here the distinction between ingroup favoritism versus outgroup derogation and aggression (see Brewer, 1999 for a review). Some SIT theorists have argued that ingroup identification should primarily be associated with the former rather than the latter (Amiot \& Bourhis, 2005; Brewer, 1979, 2001). Research by Mummendey and colleagues on the positivenegative asymmetry in social discrimination (see Mummendey \& Otten, 1998 and Otten \& Mummendey, 2000 for reviews) suggests that 'positive discrimination' (biased rewarding behavior) is more readily enacted than 'negative discrimination' (biased punishing behavior) and that these two types of discrimination may be fundamentally different in terms of the contexts in which they occur. Indeed, in a recent meta-analysis performed by Buhl (1999), it was concluded that 'discrimination in the negative domain is not just discrimination in the positive domain on a lower level' (p. 57). Thus, to the extent that our VC measure taps into outgroup aggression rather than ingroup favoritism, the relatively weak relationship between ingroup identification and VC is not so surprising. Given the totality of these various considerations regarding ingroup identification, along with existing research on socio-structural parameters (e.g. group status, group permeability), we feel the relationship between identification and discrimination is likely to be far more subtle and complex than previously imagined (see Aberson \& Howanski, 2002; Bettencourt et al., 2001).

In conclusion, the principal aim of this research was to better understand why people would choose to engage in a VC allocation strategywillingly sacrificing absolute ingroup profits in favor of relative, ingroup-over-outgroup, profits. While the expected effects for ethnic identification did not obtain here, as described above, there was nonetheless good evidence that both perceived group competition and SDO are implicated in VC decisions. Future research on VC should seek not only to uncover when and why social identification will be most relevant, but also to address questions about the contextual generalizability of the present findings. Namely, will the tendency to make Vladimir's choice always be related to perceived group competition and SDO-when using different types of dependent measures; across different decision-making contexts; with different types of groups; and in different cultures? Isn't it possible, for example, that the tendency for people to see social groups as locked into zero-sum relationships is present only in some (highly competitive) cultures, and 
that perceived competition is thus not relevant in other (more collaborative and communal) cultures? Even within a given culture, it is not clear that perceived competition and SDO will relate to VC equally strongly for members of both dominant and subordinate groups. Indeed, what is known as the 'ideological asymmetry hypothesis' within social dominance theory would suggest that VC would be more positively associated with SDO among members of dominant rather than subordinate groups (see Sidanius \& Pratto, 1999). Examining these types of questions will be important in helping us to develop a more complete understanding of when and why VC, as opposed to other forms of ingroup bias, is most likely to occur.

\section{Note}

1. No pull scores were calculated because only one specific type of matrix was employed in the present study (i.e. maximum differentiation pitted against a combination of maximum ingroup profit and maximum joint profit) and a minimum of two different matrices are required to calculate a pull (or difference) score (see Bourhis et al., 1994 for further details).

2. The task asked participants to "Assume that the Regents of the University of California have decided to allocate an unspecified amount of money to the support of various ethnic student organizations. Some of these consist of predominantly White students while others consist of primarily minority students'. Participants were asked to check one of seven alternatives to "indicate which combination you feel should be allocated to the student organizations'. The steps in the scale (in \$million for White:Minority) were 7:1, 9:5, 11:9, $13: 13,15: 17,17: 21$, and 19:25.

\section{Acknowledgment}

This research was conducted with support from the Russell Sage Foundation.

\section{References}

Aberson, C. L., \& Howanski, L. M. (2002). Effects of self-esteem, status, and identification on two forms of ingroup bias. Current Research in Social Psychology, 7, 225-243.
Aiken, L. S., \& West, S. G. (1991). Multiple regression: Testing and interpreting interactions. Thousand Oaks, CA: Sage.

Amiot, C. E., \& Bourhis, R. Y. (2005). Ideological beliefs as determinants of discrimination in positive and negative outcome distributions. European Journal of Social Psychology, 35, 581-598.

Becker, G. S. (1957). The economics of discrimination. London: University of Chicago Press.

Bettencourt, B. A., Charlton, K., Dorr, N., \& Hume, D. L. (2001). Status differences and in-group bias: A meta-analytic examination of the effects of status stability, status legitimacy, and group permeability. Psychological Bulletin, 127, 520-542.

Billig, M., \& Tajfel, H. (1973). Social categorization and similarity in intergroup behaviour. European Journal of Social Psychology, 3, 27-52.

Bobo, L. (1988). Group conflict, prejudice, and the paradox of contemporary racial attitudes. In P. A. Katz \& D. A. Taylor (Eds.), Eliminating racism: Profiles in controversy (pp. 85-116). New York: Plenum.

Bourhis, R. Y., \& Gagnon, A. (2001). Social orientations in the minimal group paradigm. In R. Brown \& S. L. Gaertner (Eds.), Blackwell handbook of social psychology: Intergroup processes (pp. 89-111). Oxford, UK: Blackwell.

Bourhis, R. Y., Sachdev, I., \& Gagnon, A. (1994). Intergroup research with the Tajfel matrices: Methodological notes. In M. P. Zanna \& J. M. Olson (Eds.), The psychology of prejudice: The Ontario Symposium (Vol. 7, pp. 209-232). Hillsdale, NJ: Erlbaum.

Brewer, M. B. (1979). In-group bias in the minimal intergroup situation: A cognitive-motivational analysis. Psychological Bulletin, 86, 307-324.

Brewer, M. B. (1999). The psychology of prejudice: Ingroup love or outgroup hate? Journal of Social Issues, 55, 429-444.

Brewer, M. B. (2001). Ingroup identification and intergroup conflict: When does ingroup love become outgroup hate? In R. D. Ashmore, L. Jussim, \& D. Wilder (Eds.), Social identity, intergroup conflict, and conflict reduction (pp. 17-41). Oxford, UK: Oxford University Press.

Buhl, T. (1999). Positive-negative asymmetry in social discrimination: Meta-analytical evidence. Group Processes $\mathcal{E}$ Intergroup Relations, 2 (1), 51-58.

Crisostomo, L. A. (2001, November). Neo-segregation occurring on campus. The Badger Herald Online. http:/ /www.badgerherald.com/vnews/display. v/ART/2001/11/19/3bf9cfbb438e2.

Gagnon, A., \& Bourhis, R. Y. (1996). Discrimination in the minimal group paradigm: Social identity 
or self-interest? Personality and Social Psychology

Bulletin, 22, 1289-1301.

Hinkle, S., \& Brown, R. (1990). Intergroup comparisons and social identity: Some links and lacunae. In D. Abrams \& M. A. Hogg (Eds.), Social identity theory: Constructive and critical advances (pp. 48-70). New York: Harvester Wheatsheaf.

Hogg, M. A., \& Abrams, D. (1990). Social identifications: A social psychology of intergroup relations and group processes. London: Routledge.

Jaret, C., \& Reitzes, D. C. (1999). The importance of racial-ethnic identity and social setting for Blacks, Whites, and multiracials. Sociological Perspectives, 42, 711-737.

Larkey, L. K., \& Hecht, M. L. (1995). A comparative study of African American and European American ethnic identity. International Journal of Intercultural Relations, 19, 483-504.

Mummendey, A., \& Otten, S. (1998). Positivenegative asymmetry in social discrimination. In W. Stroebe \& M. Hewstone (Eds.), European review of social psychology (Vol. 9, pp. 107-143). New York: Wiley.

Otten, S., \& Mummendey, A. (2000). Valencedependent probability of ingroup favoritism between minimal groups: An integrative view on the positive-negative asymmetry in social discrimination. In D. Capozza \& R. Brown (Eds.), Social identity processes (pp. 33-48). London: Sage.

Perreault, S., \& Bourhis, R. Y. (1998). Social identification, interdependence and discrimination. Group Processes E Intergroup Relations, 1, 49-66.

Pratto, F., Sidanius, J., Stallworth, L. M., \& Malle, B. F. (1994). Social dominance orientation: A personality variable predicting social and political attitudes. Journal of Personality and Social Psychology, 67, 741-763.

Sidanius, J., \& Pratto, F. (1999). Social dominance: An intergroup theory of social hierarchy and oppression. New York: Cambridge University Press.

Tajfel, H. (1978). Differentiation between social groups. London. Academic Press.
Tajfel, H., Billig, M. G., Bundy, R. P., \& Flament, C. (1971). Social categorization and intergroup behaviour. European Journal of Social Psychology, 1, 149-178.

Tajfel, H. \& Turner, J. C. (1986). The social identity theory of intergroup behavior. In S. Worchel \& W.A. Austin (Eds.), Psychology of intergroup relations (pp. 7-24). Chicago: Nelson Hall.

Turner, J.C. (1975). Social comparison and social identity: Some prospects for intergroup behavior. European Journal of Social Psychology, 54, 101-114.

Turner, J. C. (1999). Some current issues in research on social identity and self-categorization theories. In N. Ellemers, R. Spears \& B. Doosje (Eds.), Social identity: Context, commitment, content (pp. 6-34). Oxford:

Blackwell Science.

Turner, J. C., Hogg, M. A., Oakes, P. J., Reicher, S. D., \& Wetherell, M. S. (1987). Rediscovering the social group: A self categorization theory. Cambridge, MA: Basil Blackwell.

Paper received 3 November 2004; revised version accepted 10 February 2006.

\section{Biographical notes}

JIM SIDANIUS is a full professor in the departments of psychology and African and African American studies at Harvard University.

HILLARY HALEY is a lecturer in the department of psychology at the University of California, Los Angeles (UCLA).

LUDWIN MOLINA is a PhD candidate in the department of psychology at the University of California, Los Angeles (UCLA).

FELICIA PRATTO is a full professor of psychology in the department of psychology at the University of Connecticut. 